\title{
ЭМБОЛИЗАЦИЯ БРОНХИАЛЬНЫХ АРТЕРИЙ КАК АКТИВАТОР ФАКТОРА НЕКРОЗА ОПУХОЛИ
}

\author{
В. Е. Севергин ${ }^{1}$, П. П. Шипулин ${ }^{1}$, А. И. Ткаченко ${ }^{2}$, Е. Ю. Тронина ${ }^{2}$, М. Ю. Голубенко ${ }^{2}$, \\ О. М. Каланжова ${ }^{2}$, Е. Н.Степановичус ${ }^{2}$
}

${ }^{1}$ Одесская областная клиническая больница, ²Одесский национальный медицинский университет

\section{BRONCHIAL ARTERIES EMBOLIZATION AS AN ACTIVATOR OF TUMOR NECROSIS FACTOR}

\author{
V. E. Severgin'1, P. P. Shipulin', A. I. Tkachenko², E. Yu. Tronina², M. Yu. Golubenko², \\ O. M. Kalanzhova², E. N. Stepanovichus ${ }^{2}$ \\ ${ }^{1}$ Odessa Regional Clinical Hospital, \\ ${ }^{2}$ Odessa National Medical University
}

\begin{abstract}
Рефрерат
Цель. Анализ результатов лечения больных по поводу центрального рака легких (ЦРЛ) с использованием рентгеноэндоваскулярной эмболизации (РЭЭ) бронхиальных артерий (БА) и эндобронхиальной радиочастотной абляции (РЧА) с реканализацией участков опухолевого стеноза.

Материалы и методы. Проанализированы результаты лечения 125 пациентов по поводу ЦРЛ, осложненного опухолевым стенозом бронхов и легочным кровотечением. ЦРЛ ІІІА стадии диагностирован у 25 больных, IIIB стадии - у 62, IV стадии - у 38. Всем пациентам первым этапом выполняли РЭЭБА с использованием полиуретановых эмболов, вторым этапом - эндобронхиальную РЧА участков опухолевого стеноза с применением аппарата ЭХВЧ-150 Фотек, мощностью 60 Вт.

Результаты. По данным контрольной бронхофиброскопии отмечен некроз опухоли с признаками гнойного эндобронхита. У всех пациентов удалось достичь реканализации бронхов, гемостатический эффрект отмечен у $90 \%$. Под влиянием комплексного лечения у 9 пациентов при правосторонней локализации опухоли отмечен ее регресс с формированием локального пневмофиброза и пневмосклероза.

Выводы. Применение РЭЭБА вследствие некроза опухоли способствовало активации фрактора некроза опухоли- $\alpha$ (ФНО- $\alpha$ ), который играет ведущую роль в течении заболевания у пациентов с единственной правой бронхиальной артерией.

Ключевые слова: рак легкого; фрактор некроза опухоли-а; эмболизация бронхиальных артерий.

Abstract

Objective. Analysis of patients treatment results with the central lung cancer (CLC) using X-ray endovascular embolization of bronchial arteries (EEBA) and endobronchial radiofrequency ablation (RFA) with tumor stenosis recanalization.

Matherials and methods. The results of 125 patients treatment with CLC complicated by tumor bronchial stenosis and pulmonary hemorrhage were analyzed. CLC IIIA stage was diagnosed in 25 patients, IIIB stage - in 62, IV stage - in 38.

All patients received at the first stage EEBA using polyurethane emboli, the second stage - endobronchial RFA of tumor stenosis recanalization with Fotek-150 device with $60 \mathrm{~W}$ power.

Results. For control bronchofibroscopy, tumor necrosis with purulent endobronchitis was observed.

All patients achieved recanalization of the bronchi, the hemostatic effect was achieved in $90 \%$. As complex treatment 9 patients with on the right tumor localization had tumor regression the formation of local pneumofibrosis and pneumosclerosis.

Conclusions. The EEBA use is causing tumor necrosis to promote the tumor necrosis factor- $\alpha$ (TNF- $\alpha$ ) activation, which plays a decisive role in patients disease course with a single right bronchial artery.

Keywords: lung cancer; tumor necrosis factor- $\alpha$; embolization of bronchial arteries.
\end{abstract}

В настоящее время проблема рака легких не решена, несмотря на определенные успехи торакальной онкологии. В связи с этим у значительного числа больных применяют паллиативное и симптоматическое лечение. Скрытое течение опухолевого процесса и длительное отсутствие клинических проявлений во многом определяют трудности своевременной диагностики рака легких.
Большинство пациентов при впервые установленном заболевании обращаются за медицинской помощью в связи со значительным распространением бластоматозных изменений в легком и грудной полости [1].

Так, из числа больных, госпитализированных в онкологические и хирургические лечебные учреждения, ЦРЛ III и IV стадии устанавливают у $40-75 \%$, IV стадии - у 12\% [2].
Наличие у таких больных типичных осложнений распространенного опухолевого процесса не позволяет применять химиотерапию и лучевую терапию. Присоединение кровохарканья либо легочного кровотечения является одним из наиболее тягостных симптомов нерезектабельного рака. При раке легкого кровотечение как начальный симптом заболевания отмечают у 20\% пациентов, в терминальных стади- 
ях - у 60\%, наличие полного или частичного опухолевого стеноза трахеи и бронхов также ухудшает состояние больных.

Это обусловлено снижением функции дыхания, интоксикацией вследствие нарушения дренажной функции бронхов, скоплением мокроты, ее нагноением.

Кроме того, пожилой возраст пациентов и наличие сопутствующих заболеваний делают невозможным проведение радикального лечения даже в отсутствие признаков неоперабельности.

Внедрение таких нестандартных технологий, как РЭЭБА [3], эндоскопическая реканализация опухолевого стеноза дыхательных путей путем РЧА [4] обеспечило условия для оказания помощи таким больным.

Цель исследования: анализ результатов лечения больных по поводу ЦРЛ с использованием методов РЭЭБА и эндобронхиальной РЧА с реканализацией опухолевого стеноза.

\section{МАТЕРИАЛЫ И МЕТОДЫ ИССЛЕДОВАНИЯ}

В клинике с использованием указанных технологий по поводу ЦРЛ, осложненного опухолевым стенозом трахеи и бронхов, а также легочным кровотечением и кровохарканьем, лечили 125 пациентов, в том числе 86 мужчин и 39 женщин. ЦРЛ IIІА стадии диагностирован у 25 больных, IIIB стадии - у 62, IV стадии - y 38.

Показанием к паллиативному лечению были наличие тяжелых сопутствующих заболеваний, а также распространенность опухолевого процесса.

Всем пациентам первым этапом выполняли РЭЭБА. Под местной анестезией катетеризировали бедренную артерию по Сельдингеру. В грудную часть аорты проводили катетер типа Cobra, с помощью которого осуществляли визуализацию и последующую эмболизацию бронхиальных артерий с применением полиуретановых эмболов диаметром 420-750 мкм либо микроспиралей. Непосредственный положительный эффект РЭЭБА в виде полного прекращения кровотечения и кровохарканья наблюдали у 89,8\% пациентов.

Вторым этапом выполняли эндобронхиальную РЧА с реканализацией опухолевого стеноза. Все оперативные вмешательства осуществляли под местной анестезией с помощью бронхофиброскопа Olympus, в последнее время мы также использовали видеобронхоскоп Pentax. В рабочий канал бронхофиброскопа вводили электрод, с помощью которого проводили реканализацию участка опухолевого стеноза. В качестве источника тока высокой частоты использовали аппарат ЭХВЧ-150 Фотек, мощностью 60 Вт, продолжительность экспозиции 2-3 мин, число необходимых эндобронхиальных вмешательств в среднем около 4.

После выполнения РЭЭБА на 4-5-е сутки отмечали возникновение гнойного эндобронхита различной интенсивности. На протяжении 2 нед после эмболизации количество гнойной мокроты составляло в среднем 200-300 мл. Также практически у всех пациентов отмечали повышение температуры тела до 38 - $39{ }^{\circ} \mathrm{C}$, незначительное похудение, симптомы интоксикации.

По данным контрольной бронхофиброскопии отмечен некроз опухоли с признаками гнойного эндобронхита. Чаще всего эти симптомы возникали у пациентов при локализации опухоли в правом легком. По данным литературы [5] и нашим наблюдениям, у 40\% пациентов правое легкое кровоснабжалось одной бронхиальной артерией, тогда как слева число артерий от 2 до 4, наиболее часто бронхиальные артерии отходили от грудной части аорты (у 46,6\%), правой межреберной артерии (у 22,7\%) [6], бронхиальные артерии кровоснабжали не только стенку бронхов, но и перибронхиальную клетчатку, внутрилегочные лимфатические узлы, нервы, сосуды легких [6].

\section{РЕЗУЛЬТАТЫ}

Одна правая бронхиальная артерия обнаружена у 26 (38,8\%) пациентов.

После проведенного комплексного лечения (РЭЭБА, эндобронхиаль- ная РЧА, лучевая терапия в суммарной дозе 60 Гр) у 9 пациентов при правосторонней локализации опухоли отмечен ее регресс с формированием локального пневмофиброза и пневмосклероза (у 4 - ЦРЛ ІІІА стадии, у 5 - ІІІВ стадии). У 8 больных по данным гистологического исследования верифицирован плоскоклеточный рак, у 1 пациентки - аденокарцинома, пациентка умерла через 1,5 мес после лечения от правосторонней пневмонии, осложненной абсцессом верхней доли правого легкого, септическим шоком, дыхательной недостаточности III стадии. Заключение патологоанатомического исследования: правосторонняя верхнедолевая пневмония, осложнившаяся острым абсцессом верхней доли правого легкого, атипичные клетки не обнаружены.

\section{ОБСУЖДЕНИЕ}

У некоторых пациентов при центральном раке правого легкого и единственной бронхиальной артерии в ранние сроки возникает некроз опухоли с последующим формированием локального фиброза. Один пациент из этой группы прожил 45 мес, умер от легочного кровотечения; 4 пациента - 30 мес, умерли от сопутствующих заболеваний; 3 пациента живы более 27 мес.

Анализируя результаты нашего исследования и данные литературы [7], мы пришли к выводу, что решающую роль в течении заболевания после комплексного лечения у пациентов при единственной правой бронхиальной артерии играет ФНО- $\alpha$.

Еще в конце XVIII в. врачи заметили уменьшение или исчезновение раковых опухолей у пациентов после инфекционных заболеваний.

В начале XX в. W. B. Coley [8] попытался воспроизвести это явление путем инъекции пациентам с онкологическим заболеванием живых или убитых грамположительных или грамотрицательных микроорганизмов, а также препаратов, полученных путем фильтрования их культур.

Несмотря на то, что в целом применение такой терапии было отклонено из-за высокой токсичности, отдельные наблюдения успешного излечения подробно описаны и ста- 
ли основой фундаментального исследования [9].

В 1975 г. Е. A. Carswell и соавторы [7] продемонстрировали, что при заражении мышей БЦЖ, стимулировавшими систему сосудистого эндотелия, последующая инъекция липополисахаридов способствовала продукции белкового компонента, названного ими ФНО- $\alpha$.

ФНО- $\alpha$ (кахектин) синтезируется моноцитами, макрофагами и Тлимфоцитами. Он оказывает цитотоксическое действие на определенные клетки опухолей путем геморрагического некроза.

ФНО- $\alpha$ - это пироген, играет важную роль в патогенезе септического шока. Под влиянием ФНО- $\alpha$ значительно увеличивается образование макрофагами и нейтрофильными гранулоцитами перекиси водорода и других свободных радикалов. Покоящиеся клетки, макро-

\section{REFERENCES}

1. Bisenkov LN. Torakalnaja hirurgija. SPb.: Gippokrat; 2004. 928 s. [In Russian].

2. Berjozkin DP, Filatov VN. Otnositelnaja pjatiletnjaja vyzhivaemost bolnyh s osnovnymi formami zlokachestvennyh novoobrazovanij. Voprosy Onkologii. 1989; 5: 583-4. [In Russian].

3. Severgin VE, Shipulin PP, Agrahari A, Tronina EJu, Kiriljuk AA, Poljak SD i dr. Vozmozhnosti primenenija jendovaskuljarnogo gemostaza pri lechenii ljogochnogo krovotechenija. Klinichna Khirurhiia. 2015; (6): 46-8. [In Russian].

4. Severgin VE, Shipulin PP, Agrahari A, Poljak SD, Kanzho N, Tronina EJu. Vozmozhnosti nestandartnyh hirurgicheskih tehnologij $v$ palliativnom lechenii raka ljogkogo. Klinichna Khirurhiia. 2016; (6): 52-5. [In Russian].
5. Cauldwell EW, Siekert RG. The bronchial arteries; an anatomic study of 150 human cadavers. Surg. Gynecol. Obstet. 1948 Apr; 86(4): 395-412.

6. Bolenga ASJ. Selective bronchial and intercostal arteriography. Springer, Leiden. 1970; 207 p. DOI: 10.1007/978-94-010-3156-1.

7. Carswell EA, Old LJ, Kassel RL, Green S, Fiore N, Williamson B. An endotoxin induced serum factor that causes necrosis of tumors. Proc. Natl. Acad. Sci. USA. 1975 Sep; 72(9): 3666-70.

8. Coley WB. The treatment of malignat inoperable tumors with the mixed toxins of erysipelas and bacillus prodigiosus. Brussels; M. Weissenbruch; 1914.

9. Bickels J, Kollender Y, Merinsky O, Meller I. Coley's toxin: historical perspective. Isr. Med. Assoc. J. 2002 Jun; 4(6): 471-2. 